\title{
Las reformas educativas en México. Campo de fuerzas en disputa
}

\section{Educational reforms in Mexico: a battlefield of forces in dispute}

DOI: https://doi.org/10.32870/dse.v0i23.958

\section{Jacinta Hernández Pérez*}

Ornelas, C. (2018). La contienda por la educación. Globalización, neocorporativismo y democracia. México: Fondo de Cultura Económica, 437 pp. ISBN 978-607-16-5900-2.

Las reformas que caracterizan el sistema educativo en México plantean como intencionalidad común mejorar la educación: que sea de mayor calidad, más equitativa e igualitaria. Históricamente, estas se identifican por el gobierno que las instituye y el presidente que lo representa, quienes se sitúan como principales actores políticos dentro de los juegos del poder y las normas institucionales que subyacen en su diseño, implementación y evaluación. Sin embargo, existen otros actores, visibles e invisibles, cuyas acciones determinan la sinuosidad del camino que habrán de recorrer estas reformas, aunado a factores externos internacionales que orientan la política educativa de México y el mundo.

En el libro La contienda por la educación. Globalización, neocorporativismo y democracia, Carlos Ornelas hace un análisis crítico de las Reformas Educativas (RE) de los gobiernos de tres presidentes de México: Carlos Salinas de Gortari (CSG), Felipe Calderón Hinojosa (FCH) y Enrique Peña Nieto (EPN), develando la lucha permanente entre las fuerzas que se disputan el destino de la educación mexicana.

El libro consta de diez capítulos. En el primero se exponen los inicios, desarrollo y apogeo de las reformas educativas a nivel global. Ornelas señala que el concepto de reformas educativas es amplio e incluyente, que carece de definiciones precisas y es utilizado para diversos fines: justificar la política de un gobierno, promover cambios en las escuelas, así como para alinearse a proyectos emanados de organismos internacionales, entre otros.

En los capítulos segundo, tercero y cuarto, Ornelas emplea las nociones de globalización, neocorporativismo y democracia, mismas que le brindan elementos conceptuales para desplegar el análisis de las RE a nivel global desde tres corrientes teóricas: la teoría de la cultura mundial,

\footnotetext{
* Doctora en Ciencias de la Educación. Líneas de investigación: Políticas educativas, educación comparada, formación en investigación. Profesora-investigadora, Universidad Juárez Autónoma de Tabasco (UJAT). México. jacinta.hernandez@ujat.mx
} 
el neoimperialismo cultural y el modelo del prestatario y el prestamista, cuyos planteamientos permiten, entre otras cosas, identificar la influencia de la ciencia y la tecnología, los principios compartidos entre los políticos del mundo con respecto a la educación, el protagonismo de organismos internacionales y el contexto político local como un factor determinante de las RE. Con esto, prepara la antesala para entrar al ámbito de las reformas educativas nacionales.

En el capítulo quinto, se expone la conformación y desarrollo del Sindicato Nacional de Trabajadores de la Educación (SNTE) y de la Coordinadora Nacional de Trabajadores de la Educación (CNTE), así como los juegos de poder que llevaron al primero a colonizar el gobierno de la educación básica, transformándose en la principal fuerza hegemónica del sistema educativo mexicano, y a la segunda, en su principal contrapeso. El autor presenta con lujo de detalles, hechos, lugares, nombres y circunstancias que permiten al lector hilar la información fragmentada que se tiene del sistema educativo mexicano.

En los capítulos sexto y séptimo, se analizan las RE de los gobiernos de CSG, FCH y EPN. Ornelas muestra cómo eran las negociaciones entre el gobierno, el SNTE y la CNTE, así como las estrategias que utilizaban los presidentes, pero también de las que se valían los líderes sindicales y sus agremiados en la contienda por la educación. En la Reforma Educativa del gobierno de Peña Nieto, resalta la autonomía otorgada al Instituto Nacional de Evaluación Educativa (INEE) y la creación de un servicio profesional docente. Expone, además, las acciones de la Coordinadora y sus agremiados en Oaxaca, Chiapas, Michoacán y Guerrero para revocar la reforma y eliminar la evaluación docente, así como el despliegue de la tecnología del poder del gobierno por evitarlo.

En el octavo capítulo, se hace referencia a la instauración del estado evaluador a partir de las funciones del INEE, así como a la influencia de la OCDE en la educación, mientras que, en el noveno capítulo, se expone la personalidad del maestro en perspectiva histórica: desde el profesor misionero hasta el trabajador de la educación. Las escuelas normales no podían quedar fuera, y Ornelas hace un análisis de su función y de sus maestros, así como de la tecnología del poder que se ejerció, mostrando cómo la dialéctica del control no estuvo del todo tutelada por el gobierno, debido a la resistencia del gremio.

En el décimo capítulo, Ornelas retoma las tres tendencias mundiales para el análisis de las reformas: la teoría de la cultura mundial, el neoimperialismo cultural, y el prestamista y el prestatario. Ofrece interpretaciones contrastadas que parten de sus fundamentos teóricos, de la visión de sus defensores y la perspectiva de sus contendientes, poniendo en relieve que dichas teorías dejan de lado los intereses de los actores nacionales, colocándolos como simples ejecutores de políticas hechas en otras latitudes. Resalta que la RE de Peña Nieto se distingue de otras por su amplitud, la alianza entre partidos y la consecución de leyes e instituciones; sin embargo, con todo, no alcanza la hegemonía del poder y prevé que la contienda por la educación continuará en los sexenios por venir, donde la democracia y la participación se declaran 
elementos sustanciales. Concluye con un manifiesto personal en el que asienta su propio juicio sobre la reforma.

El análisis crítico de las reformas educativas que hace Carlos Ornelas de principio a fin de la obra, se fundamenta en un entramado robusto de fuentes de consulta: libros, artículos en revistas, experiencias anecdóticas, artículos periodísticos, entrevistas, tesis de maestría y doctorado, blogs, etc., con aportaciones de filósofos, políticos, sociólogos, educadores, psicólogos tanto clásicos como contemporáneos: Maquiavelo, Marx, Weber, Gramsci, Giddens, Ira Cohen, March y Olsen, Gutman, Latapí, entre otros, lo que aunado a su experiencia como analista político y a su larga trayectoria como académico e investigador de las reformas educativas de México y de otros países, dan como resultado este libro, el cual constituye una referencia obligada para quienes se interesan en el análisis de las reformas educativas en México. Por otro lado, la obra contribuye a despertar la inquietud del lector en torno a la Reforma Educativa del actual gobierno y a reflexionar por lo venidero de nuestra educación. 